\title{
Synthesis, Characterization, and Evaluation of the Antibacterial Activity of Allophylus serratus Leaf and Leaf Derived Callus Extracts Mediated Silver Nanoparticles
}

\author{
Kero Jemal, ${ }^{1}$ B. V. Sandeep, ${ }^{2}$ and Sudhakar Pola ${ }^{3}$ \\ ${ }^{1}$ College of Natural and Computational Science, Department of Biology, Dire Dawa University, P.O. Box 1362, Dire Dawa, Ethiopia \\ ${ }^{2}$ College of Science and Technology, Department of Biotechnology, Andhra University, Visakhapatnam 530003, India \\ ${ }^{3}$ Department of Biotechnology, Andhra University, Visakhapatnam 530 003, India \\ Correspondence should be addressed to Kero Jemal; kerojemal@gmail.com
}

Received 7 December 2016; Revised 26 January 2017; Accepted 6 February 2017; Published 5 March 2017

Academic Editor: Ilaria Armentano

Copyright (c) 2017 Kero Jemal et al. This is an open access article distributed under the Creative Commons Attribution License, which permits unrestricted use, distribution, and reproduction in any medium, provided the original work is properly cited.

\begin{abstract}
Allophylus serratus mediated silver nanoparticles biosynthesis, characterization, and antimicrobial activity were described. The synthesis of silver nanoparticles was confirmed by visual observation: UV-Vis spectrum, X-ray diffraction (XRD), Scanning Electron Microscopy (SEM), Energy Dispersive Spectroscopy (EDS), and Fourier Transform Infra-Red (FTIR). UVVis spectroscopy studies showed that the absorption spectra of synthesized silver nanoparticles from leaf and callus extracts had absorbance peak range of $440 \mathrm{~nm}$ and $445 \mathrm{~nm}$, respectively. The X-RD pattern revealed the presence of crystalline, dominantly spherical silver nanoparticles in the sample having size ranging from 42 to $50 \mathrm{~nm}$. The XRD peaks $38.2^{\circ}, 44.1^{\circ}, 64.1^{\circ}$, and $77.0^{\circ}$ for leaf extract and $38.1^{\circ}, 44.3^{\circ}, 64.5^{\circ}, 77.5^{\circ}$, and $81.33^{\circ}$ for callus extract can be assigned the plane of silver crystals (111), (200), (220), and (311), respectively, and indicate that the silver nanoparticles are face-centered, cubic, and crystalline in nature. SEM and EDS analysis also confirmed the presence of silver nanoparticles. The FTIR results showed the presence of some biomolecules in extracts that act as reducing and capping agent for silver nanoparticles biosynthesis. The synthesized silver nanoparticles showed significant antibacterial activity against Klebsiella pneumoniae and Pseudomonas aeruginosa.
\end{abstract}

\section{Introduction}

Nanotechnology is a field of science which deals with production, manipulation, and use of nanomaterials ranging in size from 1 to 100 nanometers. Nanomaterials have novel and enhanced useful characteristics due to their size, distribution, and morphology in comparison to the larger particles of the mass material that they have been prepared from (Wildenberg 2005). Due to their enhanced or new properties, novel applications of nanomaterials and nanoparticles are growing rapidly on various fields such as electronic, magnetic, optoelectronics, and information storage (Sun et al. 2002; Yin et al. 2003). They are also broadly applied in shampoos, detergents, soaps, cosmetics, toothpastes, and medical and pharmaceutical products (Bhattacharya and Murkherjee 2008; Bhumkar et al. 2007). Nanoparticles also have been proven to have antimicrobial activity and used in the field of medicine. They are also used in cosmetics, healthcare, biomedical, drug-gene delivery, food and feed, environment, mechanics, chemical industries, optics, electronics, space industries, energy science, catalysis, single electron transistors, light emitters, nonlinear optical devices, and photo-electrochemical applications [1].

Among nanomaterials and nanoparticles used for all the above listed purposes, the metallic nanoparticles are considered as the most promising due to their remarkable antimicrobial properties. This is of great interest for researchers due to the development of resistant strains of microbes against antibiotics [2]. Compared to other heavy metal nanoparticles, silver nanoparticles are very important because of their unique properties such as good conductivity, chemical stability, catalytic and most important antibacterial, and antiviral, antifungal, and anti-inflammatory activities. They can be incorporated into composite fibers, food industry, cryogenic 
superconducting materials, electronic components, and cosmetic products $[3,4]$. Silver nanoparticles are also applied in textile, home water purification systems, medical devices, cosmetics, electronics, and household appliances [5]. They are also being used in cancer diagnosis and treatment $[6,7]$.

Recently, synthesis of silver nanoparticles is attracting the attention of scientific community due to their wide range of applications. There are different chemical, physical, and biological methods of synthesizing nanoparticles. Most of the chemical and physical methods of silver nanoparticles synthesis are expensive and involve use of toxic and hazardous chemicals which are potentially harmful to the environment and responsible for various biological risks. Biological or green synthesis of nanoparticles by using biological materials such as plant extract, plant biomass, or microorganisms is environmentally friendly, is safe, and helps to reduce the consequence of chemical methods of nanoparticles synthesis $[8,9]$.

Some of the biological methods of silver nanoparticles synthesis involve very complex procedures. For example microbial mediated synthesis of silver nanoparticles is not industrially practical due to requirement of high aseptic and maintenance conditions [1]. Synthesis of silver nanoparticles using various plants materials and their extracts is simple way and beneficial over other biological synthesis processes which involve very complex procedures (Sastry et al. 2003) [10].

The use of plants for the synthesis of silver nanoparticles has drawn attention not only due to its nonpathogenic, environmental friendly, and economical protocol but also because of being a simple and single step rapid technique. A large number of plants and their respective portions are reported to facilitate silver nanoparticles synthesis. Plant extracts from various plants such as Alternanthera dentata [11]; Acorus calamus [12]; Boerhaavia diffusa [13]; Tea [14]; Sesuvium portulacastrum [15]; Tribulus terrestris [16]; Cocos nucifera [17]; A. indicum (Ashok et al. 2015); Ziziphora tenuior [18]; Ficus carica [19]; Cymbopogon citratus [20]; Acalypha indica [21]; Chenopodium album [22]; Cocos nucifera [17]; Pistacia atlantica [23]; Cymbopogon citratus [24], and so forth have been reported for the synthesis of silver nanoparticles.

In our present study, we investigated synthesis of silver nanoparticles from leaf and leaf derived callus extracts of Allophylus serratus, their characterization, and evaluation of antibacterial activity. This work is the first report on synthesis of silver nanoparticles using this plant which is an additional confirmation of previous reports on biological synthesis of silver nanoparticles using plant leaf and callus extracts and their antimicrobial activity.

\section{Materials and Methods}

2.1. Materials. Healthy fresh leaves of Allophylus serratus were collected from Andhra University campus in month of January 2016. The leaves were identified and authenticated by Dr. Bodaih Padal, taxonomist, Department of Botany, Andhra University, Visakhapatnam. All chemicals and reagents used in this study silver nitrate $\mathrm{AgNO}_{3}$ (99.98\%), 6Benzylaminopurine (BAP), 1-Naphthaleneacetic acid (NAA) ethanol $\left(\mathrm{C}_{2} \mathrm{H}_{6} \mathrm{O}\right)$, sodium hypochlorite $(\mathrm{NaClO})$, mercuric chloride $\left(\mathrm{HgCl}_{2}\right)$, Murashige and Skoog media (MS media), Luria Bertani broth (LB broth), and Luria Bertani agar (LB agar) were analytical grade (AR) and purchased from HiMedia, India. Double distilled water was used throughout the experiment. The bacterial strains, namely, Bacillus subtilis, Staphylococcus aureus, Klebsiella pneumoniae, and Pseudomonas aeruginosa, were obtained from Department of Microbiology, Andhra University, Visakhapatnam, India. All solutions were freshly prepared using double distilled water and kept in the dark to avoid any photochemical reactions. All glassware used in experimental procedures was washed thoroughly with double distilled water and dried using hot air oven before use.

2.2. Callus Induction and Proliferation. Callus induction of Allophylus serratus was achieved from leaf explants on MS media [25]. The PH of the media was adjusted to 5.8 and then autoclaved at $121^{\circ} \mathrm{C}$ for $15 \mathrm{~min}$ under $103.42 \mathrm{KPa}$ pressure. In laminar hood, plant growth regulators BAP (3 g/L) NAA $(0.5 \mathrm{~g} / \mathrm{L})$ were added by filter sterilization. The leaf explants were surface sterilized by using $70 \%$ ethanol for 1 minute, $2 \%$ sodium hypochlorite for 3-4 minutes, and $0.1 \%$ mercuric chloride solution for 3 minutes. Finally the leaf explants were washed thoroughly with sterile double distilled water and inoculated in the MS medium. The cultures were kept in dark at $25^{\circ} \mathrm{C}$. The induction of the callus was found within 2 weeks. The callus was subcultured every 21 days several times and finally a mass of calli was harvested after 40 days.

\subsection{Preparation of Leaf and Leaf Derived Callus Extract.} Leaves of Allophylus serratus were washed, shade dried for one week, and ground to powder. Callus induced from leaves on MS medium supplemented with $3 \mathrm{mg} / \mathrm{L}$ BAP and $0.5 \mathrm{mg} / \mathrm{L}$ NAA was grown for 40 days and collected and dried in oven at $40^{\circ} \mathrm{C}$. Then the calli were ground to powder using mortar and pestle. These powders of leaves and callus were used for the synthesis of silver nanoparticles (Figure 1).

Twenty grams of leaf and callus powder was put in $500 \mathrm{~mL}$ conical flask containing $100 \mathrm{~mL}$ double distilled water separately. The mixtures were boiled for 15 minutes. After cooled to room temperature, the mixtures were filtered with Whatman number 1 filter paper. The filtrates were stored in refrigerator $\left(4^{\circ} \mathrm{C}\right)$ and used for the synthesis of silver nanoparticles (Figure 1).

2.4. Preparation of Silver Nitrate Solution. Commercially purchased silver nitrate (molecular weight 169.87) was used to prepare $1 \mathrm{mM}$ concentration of silver nitrate solution. A stock solution of $1 \mathrm{mM}, 3 \mathrm{mM}$, and $5 \mathrm{mM}$ of $\mathrm{AgNO}_{3}$ was prepared by dissolving appropriate amount of silver nitrate in double distilled water.

2.5. Synthesis of Silver Nanoparticles. For the synthesis of silver nanoparticles, $10 \mathrm{~mL}$ of leaf extract and callus extract was mixed with $100 \mathrm{~mL}$ of aqueous $\mathrm{AgNO}_{3}$ solution separately. The synthesis process involves mixing the aqueous extracts with an aqueous solution of $\mathrm{AgNO}_{3}$ at room temperature. The mixtures were heated at $60^{\circ} \mathrm{C}$ and incubated in a dark at 


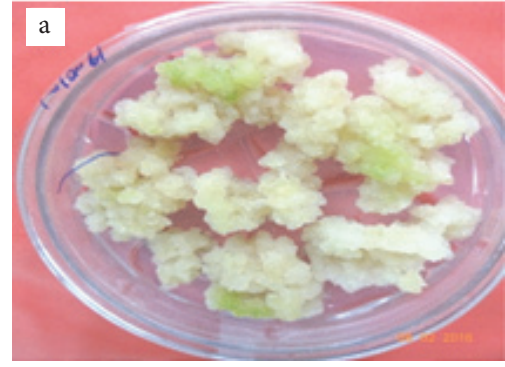

(a)

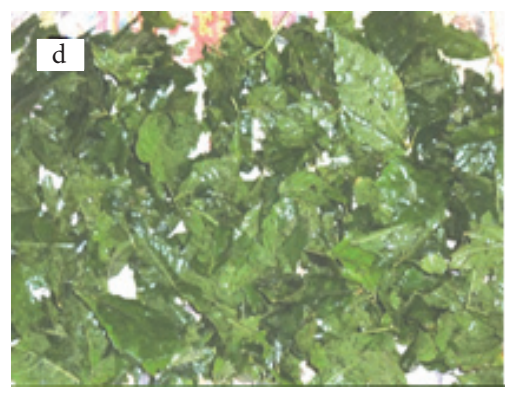

(d)

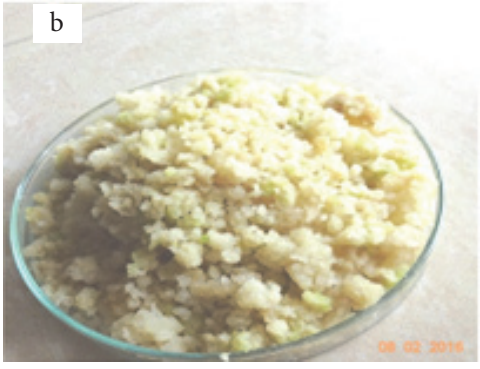

(b)

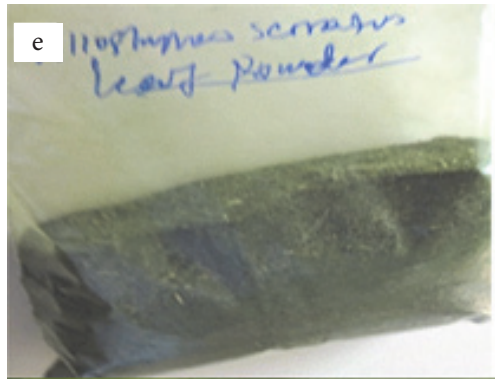

(e)

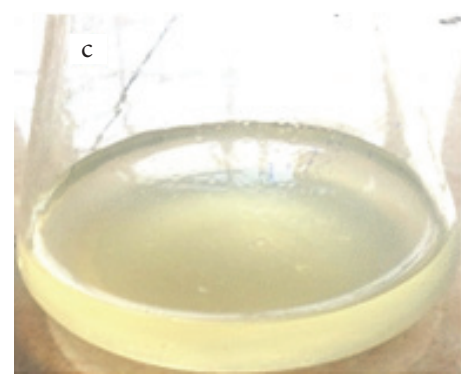

(c)

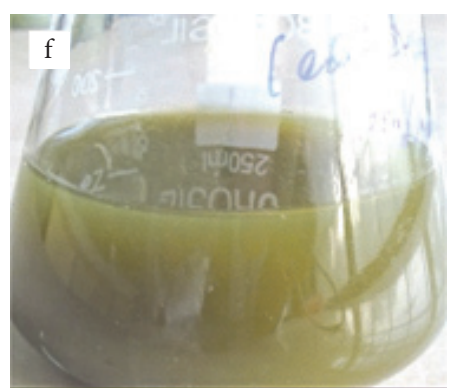

(f)

FIGURE 1: Preparation of leaf and callus extracts for the synthesis of silver nanoparticles. (a) Callus produced on MS medium +3 mg/L BAP and $0.5 \mathrm{mg} / \mathrm{L}$ NAA. (b) Callus collected after 40 days for extraction. (c) Callus extract. (d) Leaf of Allophylus serratus. (e) Dried and powdered leaf. (f) Leaf extract.

room temperature for $24 \mathrm{~h}$. The color change of the mixture was recorded.

\subsection{Characterization of Synthesized Silver Nanoparticles}

2.6.1. Visual Observation of Color Change. The synthesis of silver nanoparticles (the reduction process $\mathrm{Ag}^{+}$to $\mathrm{Ag}^{0}$ nanoparticles) was confirmed by visual observation of color change of the solution from yellow green (leaf extract) and white yellow (callus extract) to reddish brown and dark brown upon heating and incubation.

2.6.2. UV-Vis Spectroscopy. UV-Vis spectral analysis of synthesized silver nanoparticles was measured by using UVvisible spectrophotometer (UV-2450, Shimadzu, Japan) with a resolution of $1 \mathrm{~nm}$ to investigate the reduction of $\mathrm{Ag}^{+}$to $\mathrm{Ag}^{0}$ by callus and leaf extracts. The spectra were taken between 200 and $800 \mathrm{~nm}$ after $24 \mathrm{Hrs}$ incubation of the mixtures of $\mathrm{AgNO}_{3}$ solution and callus and leaf extracts. Double distilled water was used as blank reference for background correction of experiments.

2.6.3. XRD Analysis. The synthesized silver nanoparticles were centrifuged at 10,000 rpm for 15 minutes and the pellets were redispersed in sterile double distilled and centrifuged at 10,000 rpm for 10 minutes. The purified pellets were dried at $50^{\circ} \mathrm{C}$ in an oven and analyzed by X-ray Diffraction Unit (XRD) (Pan Analytical, X-pert pro, Netherland). The Xray diffraction (XRD) measurement of silver nanoparticles synthesized by leaf and callus extracts was carried out using
$\mathrm{Cu}-\mathrm{K} \alpha$ radiation source in scattering range $m(2 \theta)$ of $20-$ 80 on the instrument operating at a voltage of $45 \mathrm{kV}$ and a current of $40 \mathrm{~mA}$. The presence, crystalline nature, phase variety, and grain size of synthesized silver nanoparticles were determined by X-ray diffraction spectroscopy. The particle size of the prepared samples was determined by using Scherrer's equation as follows:

$$
D=\frac{K \lambda}{\beta 1 / 2 \cos \theta},
$$

where $D$ is average crystallite size and $\beta$ is line broadening in radians (full width at half maximum of the peak in radians). $\lambda$ is wavelength of $\mathrm{X}$-ray and $\theta$ is braggs angle. $K$ is constant (geometric factor $=0.94$ ).

\subsubsection{Scanning Electron Microscope (SEM) and Energy Disper-} sive Spectroscopy (EDS). Scanning electron microscopy study was done using electron microscope (JSM-6610 LV, Jeol Asia PTE Ltd, Japan). The synthesized silver nanoparticles were centrifuged at $10,000 \mathrm{rpm}$ for $15 \mathrm{~min}$ and the pellets were redispersed in sterile double distilled water and centrifuged at 10,000 rpm for 10 minutes. The purified pellets were dried at $50^{\circ} \mathrm{C}$ in an oven and thin films of dried samples were prepared on a carbon coated copper grid by dropping a very small amount of the samples on the grid. Extra solutions of the samples were removed using a blotting paper. The films on the carbon coated copper grid (SEM grid) were allowed to dry by putting them under a mercury lamp for $5 \mathrm{~min}$. The morphological features, micrograph images, size, and structure of synthesized nanoparticles from callus and leaf 


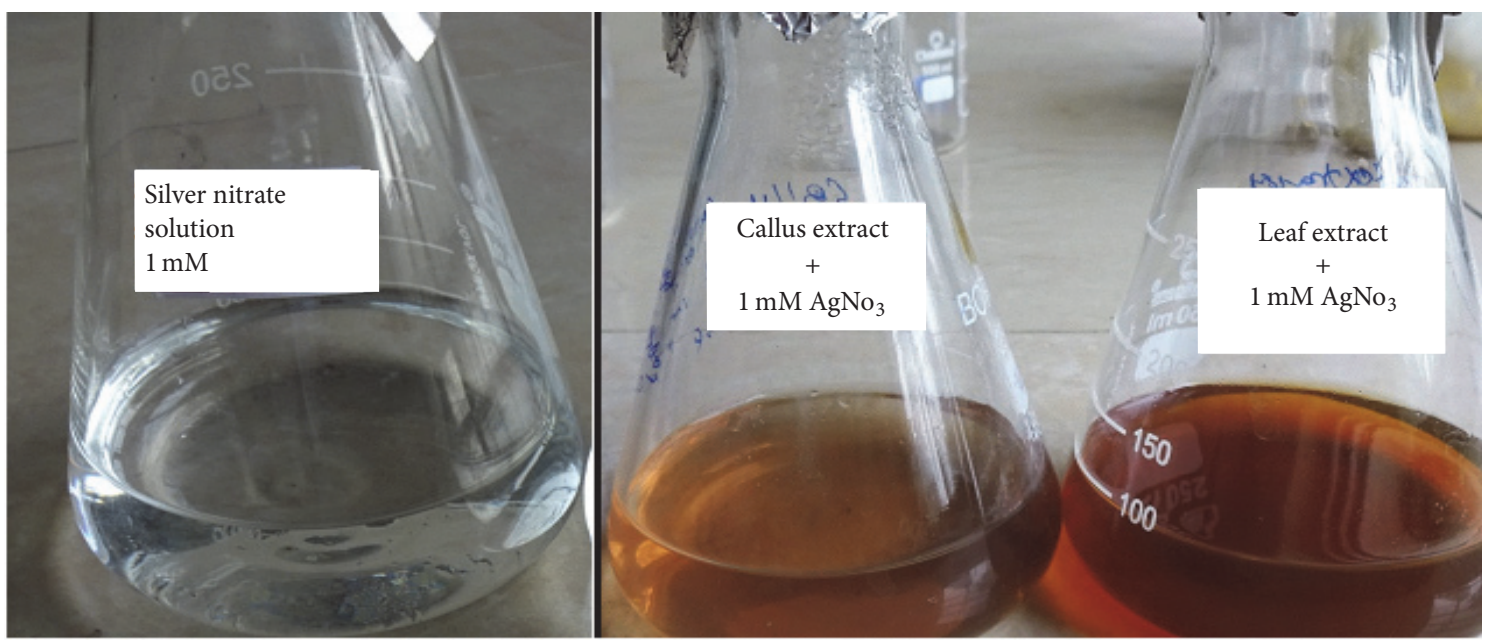

FIGURE 2: Synthesis of silver nanoparticles and its identification by the color change.

extracts were analyzed and recorded. The details regarding applied voltage, magnification used, and size of the contents of the images were implanted on the images itself. The EDS analysis was carried out by using Energy Dispersive Spectrum (INCA energy 250, Oxford, Japan).

2.6.5. FTIR Analysis. FTIR spectrometer (IR Prestige21, Shimadzu, Pvt Ltd, Japan) was used to study the chemical composition of the synthesized silver nanoparticles. The solutions containing silver nanoparticles were centrifuged at $10,000 \mathrm{rpm}$ for $15 \mathrm{~min}$. The supernatants were discarded and the pellets were redispersed in sterile double distilled water and centrifuged at $10,000 \mathrm{rpm}$ for 10 minutes. The purified pellets were dried at $60^{\circ} \mathrm{C}$ and the dried powders were subjected to FTIR spectroscopy measurement in the range $4000-400 \mathrm{~cm}^{-1}$ using $\mathrm{KBr}$ pellet method.

2.6.6. Antibacterial Assay. Antibacterial activities of synthesized silver nanoparticles were analyzed by well diffusion method against Gram's positive bacteria (Bacillus subtilis and Staphylococcus aureus) and Gram's negative bacteria (Klebsiella pneumoniae and Pseudomonas aeruginosa). The strains bacteria were subcultured using LB broth (Luria Bertani broth) (HiMedia) and were incubated at $37^{\circ} \mathrm{C}$ for $24 \mathrm{~h}$. Fresh overnight bacterial cultures were taken and spread on the LB agar (Luria Bertani agar) plates using glass rod to cultivate bacteria. Six millimeter diameter wells were made on LB agar (Luria Bertani agar) plate with the help of gel puncture. Twenty-five microlitters of silver nanoparticles, plant extract, and double distilled water (as control) were inoculated to the well, and then the plates were incubated in incubator at $37^{\circ} \mathrm{C}$ for $24 \mathrm{~h}$. The antibacterial activity was measured based on the inhibition zone around the wells.

\section{Results and Discussion}

3.1. Synthesis of Silver Nanoparticles. When leaf and callus extracts were mixed and incubated with $\mathrm{AgNO}_{3}$ solution, color change from light yellow to dark brown or reddish brown was visually observed (Figure 2 ). When the mixtures were heated at $60^{\circ} \mathrm{C}$ for 10 minutes, the color changes were more rapid than at room temperature. After heating, the mixtures were incubated at room temperature for $24 \mathrm{~h}$ for completion of the reduction process. This color change is due to the Surface Plasmon Resonance phenomenon in silver nanoparticles $[21,26]$ as a result of the excitation of free electrons in nanoparticles [27]. Similar results have also been reported in earlier studies [28-32] and hence confirmed the completion of reaction between extracts and $\mathrm{AgNO}_{3}$. No further color changes were observed after $24 \mathrm{~h}$ which indicated the completion of the reduction process. This is in line with literature reports [33] which indicated synthesis of silver nanoparticles at $24 \mathrm{~h}$ by using Lippia citriodora leaf extract. The color intensity was higher with leaf extract than callus extract (Figure 2). Control experiments without the addition of extracts showed no formation of brown color, indicating that the color change is due to the presence of extracts.

3.2. UV-Vis Spectroscopy. The formation of silver nanoparticles using leaf and leaf derived callus extracts was confirmed by measuring the UV-visible spectrum of the reaction mixture at wavelengths ranging from 200 to $800 \mathrm{~nm}$. The UVvisible absorption spectra of silver nanoparticles synthesized by using $1 \mathrm{mM} \mathrm{AgNO}_{3}$ with leaf and leaf derived callus extracts revealed a Surface Plasmon Resonance band at $440 \mathrm{~nm}$ and $445 \mathrm{~nm}$ in the spectrum, respectively, which clearly indicated the presence of spherical silver nanoparticles (Figure 3). Broadening of the peaks (Figure 3) at the base indicated that the nanoparticles are poly dispersed [34]. The difference in the intensity and the band position of leaf and callus extracts synthesized silver nanoparticles is due to leaf extracts yielding smaller and stable nanoparticles more than the callus extract.

3.3. XRD Analysis. Analysis of structure and crystalline size of the synthesized silver nanoparticles were carried out by 

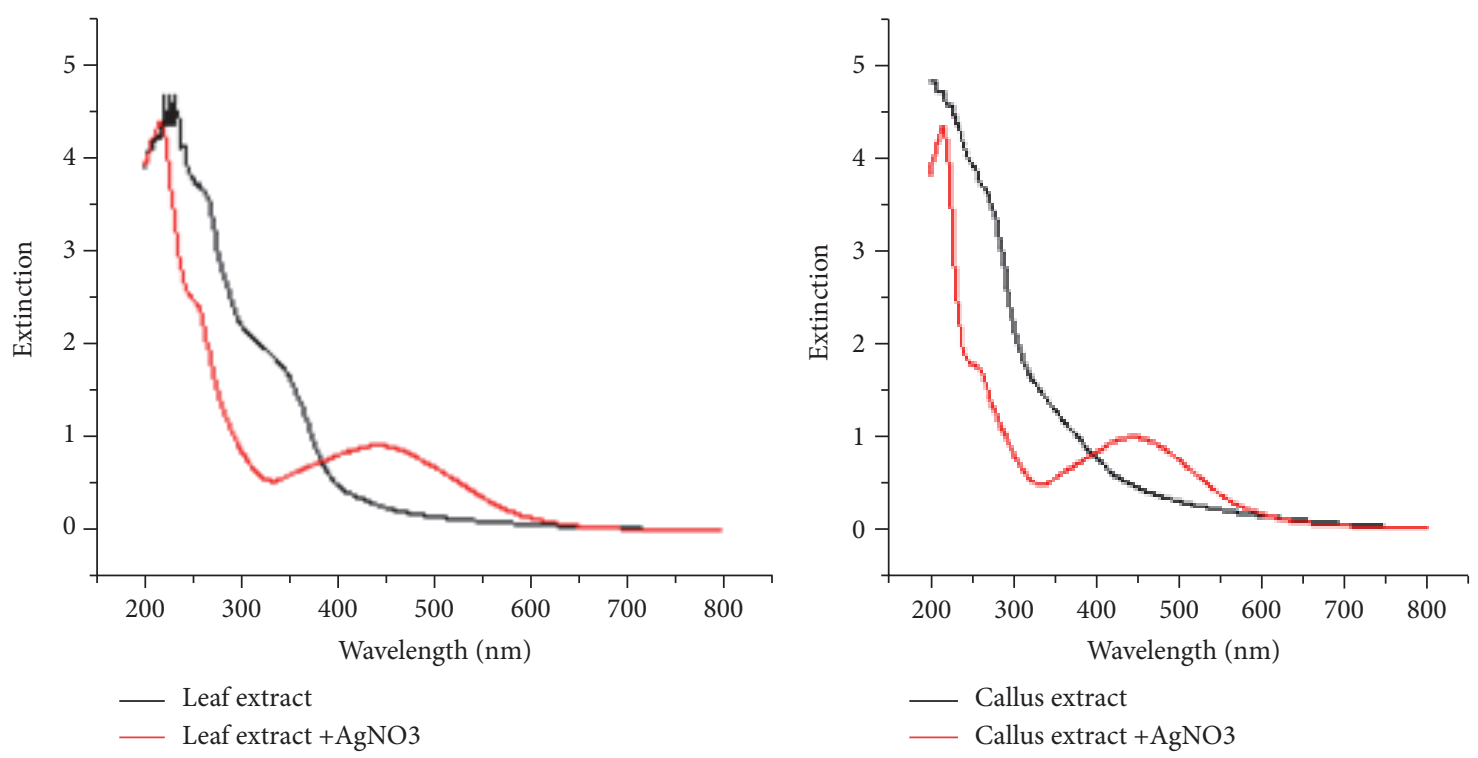

FIgURE 3: UV-vis absorption spectrum of leaf and callus extracts from Allophylus serratus treated with and without $\mathrm{AgNO}_{3}$.

XRD. The XRD analysis of synthesized silver nanoparticles from leaf extract and callus extract showed diffraction peaks at $2 \theta=32.5^{\circ}, 38.3^{\circ}, 44.4^{\circ}, 64.6^{\circ}$, and $76.8^{\circ}$ and $32.4^{\circ}, 38.3^{\circ}$, $44.5^{\circ}, 64.5^{\circ}$, and $76.7^{\circ}$, respectively. When compared with the standard, the obtained XRD spectrum confirmed that the synthesized silver nanoparticles were in nanocrystal form and crystalline in nature. The peaks can be assigned to the planes (122), (111), (200), (220), and (311) facet of silver crystal, respectively. The high peaks in the XRD analysis indicated the active silver composition with the indexing (Figure 4). The same result was reported by Roy et al. [35] and indicates that the silver nanoparticles are face-centered, cubic, and crystalline in nature (Shameli et al. 2010) (correlated to JCPDS card: number 04-0783). The Full Width at Half Maximum (FWHM) values were used to calculate the size of the nanoparticles. The average size of silver nanoparticles synthesized from leaf and callus extracts was calculated using Scherrer's equation where Scherrer's constant $K$ value = 0.94 was selected due to the cubic and crystalline nature of the nanoparticles (Scherrer [36]). The average sizes of the synthesized nanoparticles from leaf and callus extracts were found to be $42 \mathrm{~nm}$ and $44 \mathrm{~nm}$, respectively.

The broadening of Bragg's peaks around their bases indicates the formation of small sized silver nanoparticles [37-39]. A few unassigned peaks observed could be due to the presence of some bioorganic compounds/protein(s) in the leaf and callus extracts and crystallizes on the surface of the silver (Ahmad and Sharma et al. 2012). Similar results in silver nanoparticles synthesized using Mangifera indica leaf extract [40], geranium leaves [41], mushroom extract [42], and Coleus aromaticus leaf extract (Vanaja and Annadurai 2012) were reported.

3.4. Scanning Electron Microscope (SEM) and EDS Analysis. The surface morphology, size and shape of the silver nanoparticles were analyzed by Scanning Electron Microscope. Figure 5 shows the SEM image of silver nanoparticles synthesized from leaf and leaf derived callus extracts. The SEM images show individual silver nanoparticles which are predominantly spherical in shape as well as number of aggregates with no defined morphology. The presences of biomolecules in the leaf and callus extracts has resulted in the synthesis of spherical silver nanoparticles and the aggregation may be due to the presence of secondary metabolites in the leaf extracts. The SEM image shows the size of the silver nanoparticles ranging from 40 to $50 \mathrm{~nm}$. Similar result of the silver nanoparticles size was reported by using Aloe vera extract (Chandran et al. 2006) and by using Euphorbia hirta leaves (Elumalai et al. 2010).

An X-ray energy dispersive spectroscopy (EDS) study was carried out to confirm the formation of silver nanoparticles. EDS peaks corresponding to element silver show the presence of silver as the ingredient element and the formation and purity of silver nanoparticles synthesized from leaf extract and callus extracts (Figure 6). The sharp peak in the silver region was observed at $3 \mathrm{keV}$ confirming the presence of silver nanoparticles due to the Surface Plasmon Resonance [43]. Generally silver nanocrystals demonstrate typical optical absorption peak approximately at $3 \mathrm{keV}$ due to Surface Plasmon Resonance [44-46]. The EDS elemental analysis of the synthesized silver nanoparticles showed highest proportion of silver followed by $\mathrm{C}$ and $\mathrm{O}$. The weak oxygen signal may be due to X-ray emission from carbohydrates/proteins/enzymes present within the extracts [39] or possibility of silver oxide nanoparticles formation after synthesis of silver nanoparticles, which reacts with water in the solution since the nanoparticles are highly reactive due to their high surface to volume ratio [47]. Apart from this, X-ray diffraction (Figure 4) shows two peaks at 27.97 and 32.29 , which correspond to (110) and (111) planes of silver 


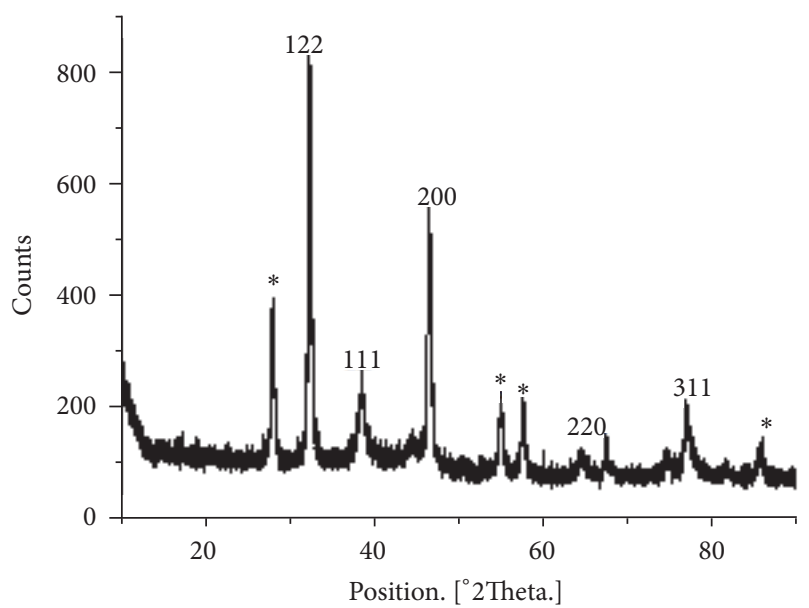

(a)

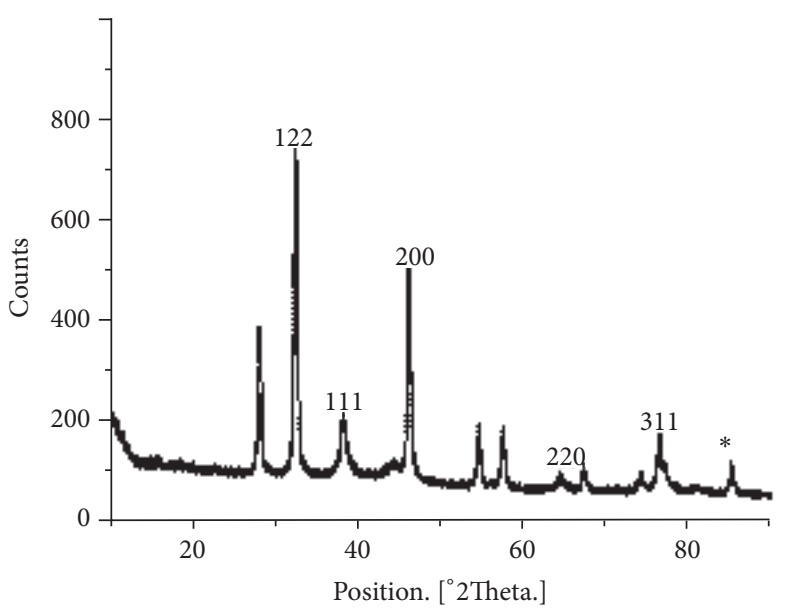

(b)

FIGURE 4: XRD diffraction pattern of silver nanoparticles synthesized from (a) aqueous leaf extract of Allophylus serratus and (b) aqueous leaf derived callus extract.

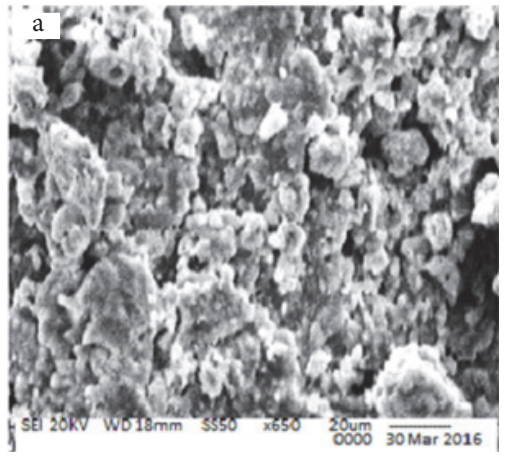

(a)

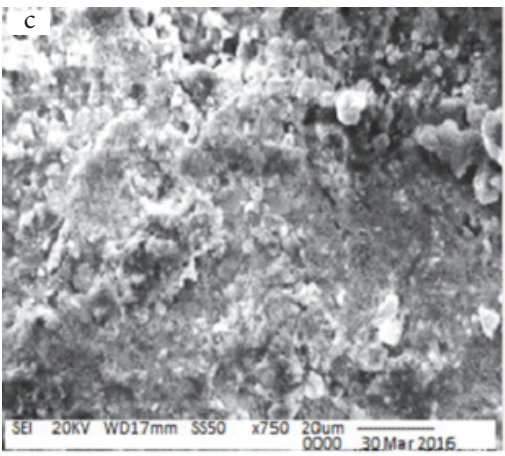

(c)

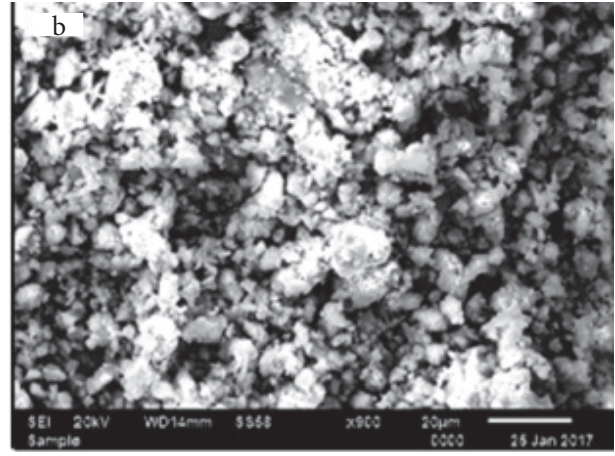

(b)

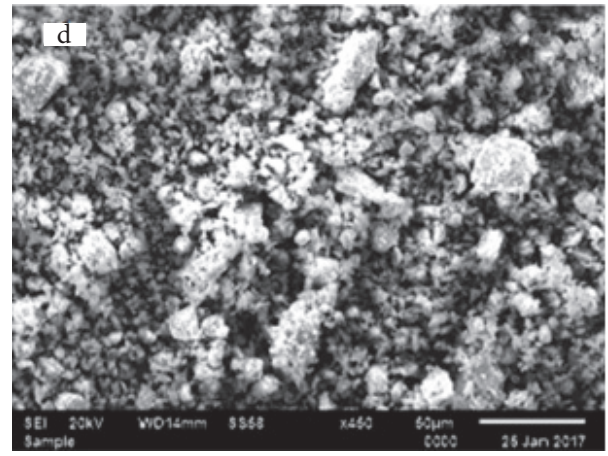

(d)

FIGURE 5: SEM image of silver nanoparticles synthesized from aqueous leaf extract (a and b) and aqueous callus extract (c and d).

oxide $\mathrm{Ag}_{2} \mathrm{O}$. These peaks correspond to silver oxide standard (JCPDS 76-1393) [48, 49] which confirms the formation of $\mathrm{Ag}_{2} \mathrm{O}$ nanoparticles. The carbon peak may be due to the biomolecules that are bound to the surface of the silver nanoparticles [50].

3.5. FTIR Analysis. FTIR analyses were carried out to identify the potential functional groups of the biomolecules in the
Allophylus serratus leaf and leaf derived callus extracts that are involved in the capping, reduction of the silver ions to synthesize silver nanoparticles, and stabilization of the synthesized silver nanoparticles. The FTIR spectrum of the leaf extract mediated synthesized silver nanoparticles is shown in Figure 7 and that of callus extract mediated synthesized silver nanoparticles is given in Figure 8, respectively. The FTIR spectra of obtained nanoparticles show different absorption 


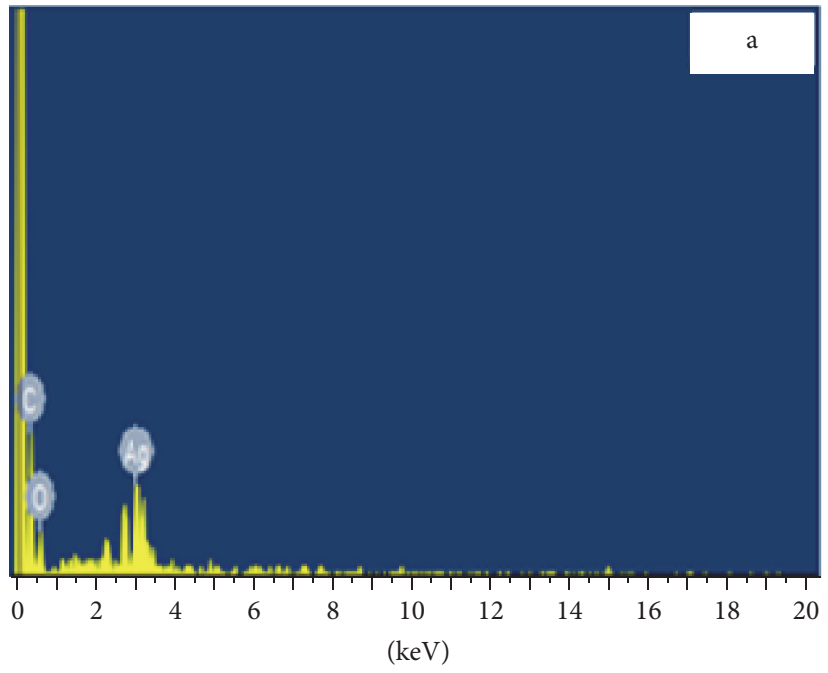

Full scale 100 cts cursor. 0.000

(a)

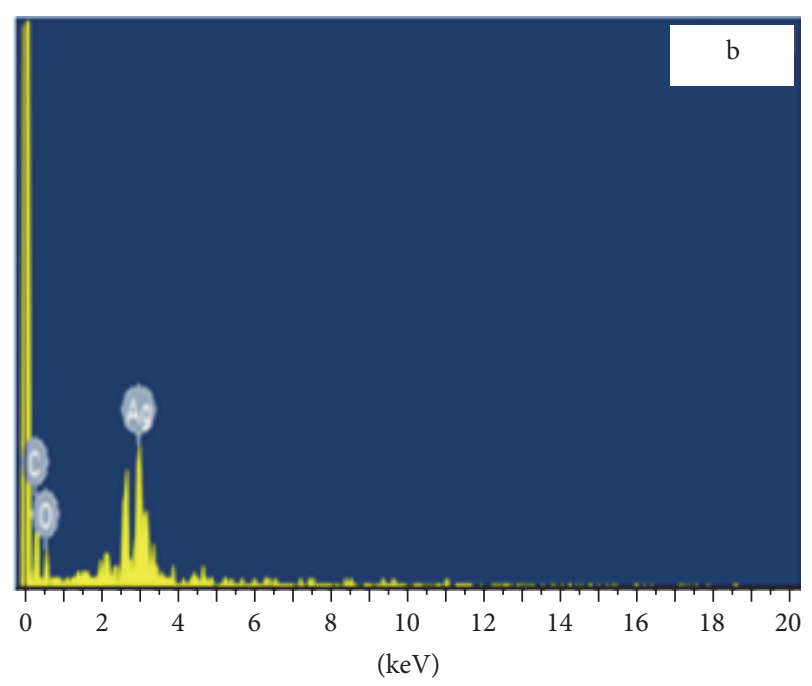

Full scale 100 cts cursor. 0.000

FIGURE 6: EDS image of synthesized silver nanoparticles from (a) leaf extract (b) leaf derived callus extracts.

bands ranging from 3550 to $532 \mathrm{~cm}^{-1}$, which indicate the presence of some active functional groups.

The absorption spectrum of leaf extract synthesized silver nanoparticles (Figure 7) shows peaks at $3267 \mathrm{~cm}^{-1}$, $2887 \mathrm{~cm}^{-1}, 2400 \mathrm{~cm}^{-1}, 2065 \mathrm{~cm}^{-1}, 1590 \mathrm{~cm}^{-1}, 1406 \mathrm{~cm}^{-1}$, $1229 \mathrm{~cm}^{-1}, 1009 \mathrm{~cm}^{-1}, 894 \mathrm{~cm}^{-1}$ and $532 \mathrm{~cm}^{-1}$. That of callus extract synthesized silver nanoparticles (Figure 8) shows peaks, $3550 \mathrm{~cm}^{-1}, 3249 \mathrm{~cm}^{-1}, 2895 \mathrm{~cm}^{-1}, 2680 \mathrm{~cm}^{-1}$, $2280 \mathrm{~cm}^{-1}, 1609 \mathrm{~cm}^{-1}, 1383 \mathrm{~cm}^{-1}, 1248 \mathrm{~cm}^{-1}, 1074 \mathrm{~cm}^{-1}$, and $895 \mathrm{~cm}^{-1}$

The absorption bands at $3550 \mathrm{~cm}^{-1}, 3267 \mathrm{~cm}^{-1}$, and $3249 \mathrm{~cm}^{-1}$ in the FTIR spectra were due to O-H stretching vibration of alcohol and phenol. The peaks at $2895 \mathrm{~cm}^{-1}$ and $2887 \mathrm{~cm}^{-1}$ were due to the presence of $\mathrm{C}-\mathrm{H}$ symmetrical stretching of hydrocarbons such as alkanes and aldehydes [51]. The band at $1609 \mathrm{~cm}^{-1}$ corresponds to $\mathrm{C}-\mathrm{N}$ and C$\mathrm{C}$ stretching indicating the presence of proteins [52]. The band at $1406 \mathrm{~cm}^{-1}$ was due to the presence of $\mathrm{N}-\mathrm{H}$ stretch vibration which showed the presence of the amide linkages of the proteins. As reported in many studies these functional groups have role in capping/stability of silver nanoparticles [52]. The bands at $1074 \mathrm{~cm}^{-1}$ and $1383 \mathrm{~cm}^{-1}$ correspond to $\mathrm{C}-\mathrm{N}$ (amines) stretch vibration of the proteins and $\mathrm{N}=\mathrm{O}$ symmetry stretching of the nitro compound, respectively. According to $[53,54]$, the carbonyl groups of the amino acid residues and the peptides, free amine, or cysteine groups in proteins have the ability to bind to the silver. The band at $532 \mathrm{~cm}^{-1}$ indicates $\mathrm{C}-\mathrm{Br}$ stretching of alkyl halides and that at $1248 \mathrm{~cm}^{-1}$ and $1229 \mathrm{~cm}^{-1}$ were assigned to $\mathrm{C}-\mathrm{N}$ stretching of amines.

Therefore, from the results of FTIR analyses of extracts mediated synthesized silver nanoparticles it can be concluded that some of the biological molecules of leaf and callus extracts such as alkaloids, phenols, flavonoids, amino acids,

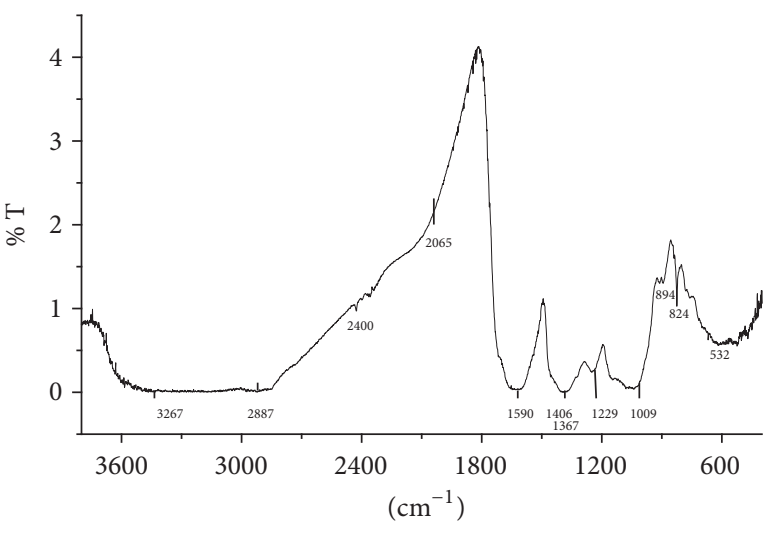

FIGURE 7: FTIR spectroscopic micrograph of synthesized silver nanoparticles using leaf extract.

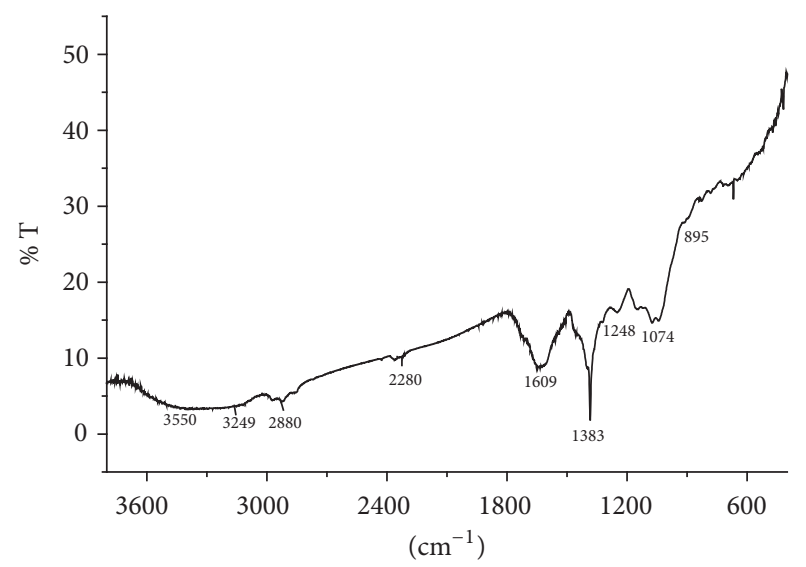

FIGURE 8: FTIR spectroscopic micrograph of synthesized silver nanoparticles using callus extract. 
TABLE 1: Zones of inhibitions of silver nanoparticles obtained from antibacterial activity.

\begin{tabular}{|c|c|c|c|c|}
\hline \multirow{2}{*}{ Bacterial species } & \multicolumn{4}{|c|}{ Diameter of inhibition zone (mean of triplicates) $(\mathrm{mm})$} \\
\hline & Silver nanoparticles from leaf extract & Silver nanoparticles from callus extract & Control & Leaf and callus extracts \\
\hline Staphylococcus aureus & 10 & 6 & 19 & 0 \\
\hline Bacillus subtilis & 8 & 7 & 20 & 0 \\
\hline Klebsiella pneumoniae & 14 & 13 & 22 & 0 \\
\hline Pseudomonas aeruginosa & 14 & 12 & 20 & 0 \\
\hline
\end{tabular}

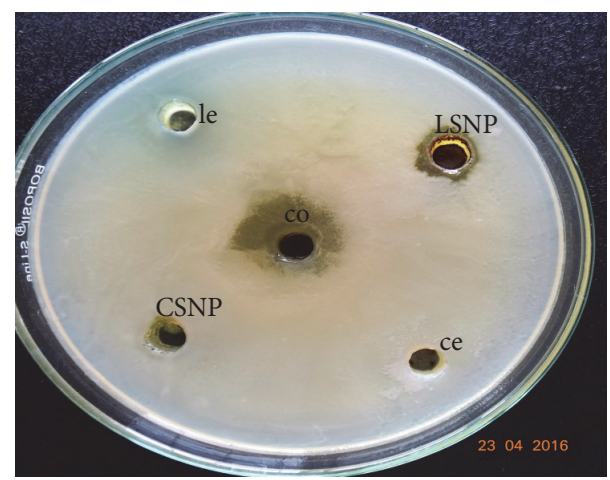

(a)

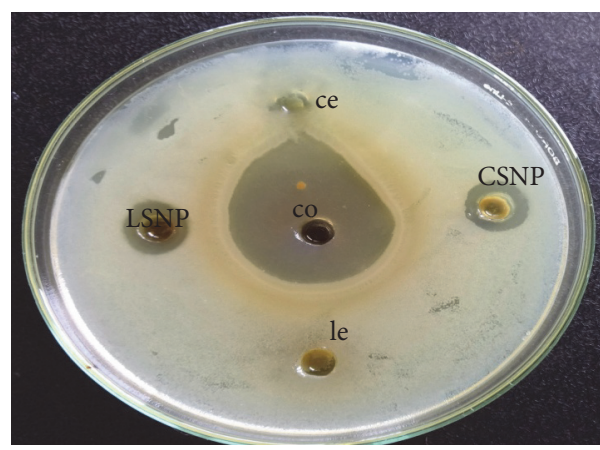

(c)

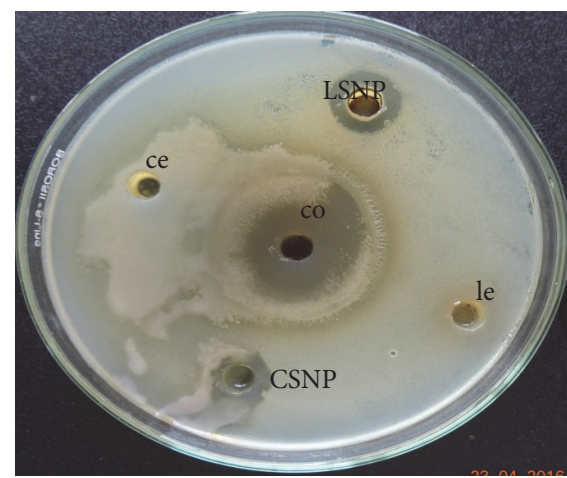

(b)

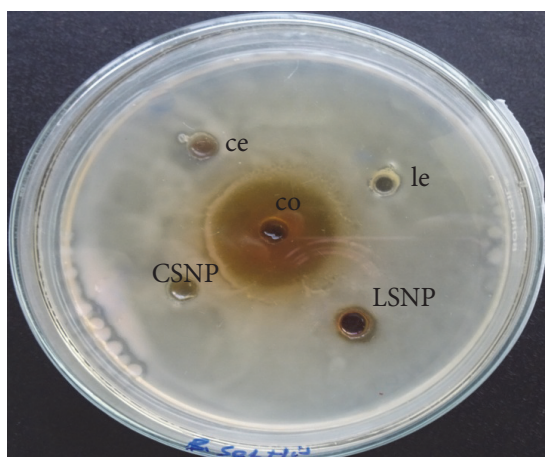

(d)

FIGURE 9: Antibacterial activity of A. serratus leaf and callus extract mediated synthesized silver nanoparticles: (a) Staphylococcus aureus, (b) Pseudomonas aeruginosa, (c) Klebsiella pneumoniae, and (d) Bacillus subtilis.

glycosides, and tannins are responsible for biotransformation of silver ions to silver nanoparticles and its stabilization in aqueous medium.

3.6. Antibacterial Activity. Silver nanoparticles have been widely used in health, medicine, and environmental applications [55]. In this study, Allophylus serratus leaf and leaf derived callus extracts mediated synthesized silver nanoparticles were examined for possible antibacterial activity. The synthesized silver nanoparticles were tested for antibacterial activity against both Gram's positive (Bacillus subtilis and Staphylococcus aureus) and Gram's negative (Klebsiella pneumoniae and Pseudomonas aeruginosa) bacteria. Table 1 and Figure 9 show the results of antibacterial activities of synthesized silver nanoparticles evaluated from the well diffusion method.

The synthesized silver nanoparticles tested for antibacterial activity showed inhibition zones against the studied bacteria (Figure 9). Maximum zone of inhibition $14 \mathrm{~mm}$ was produced against Klebsiella pneumoniae and Pseudomonas aeruginosa, respectively. The least zone of inhibition was observed in Staphylococcus aureus species (Figure 1 and Table 1). The silver nanoparticles showed antibacterial activity due to their large surface area that provides better contact with cell wall of bacteria [56]. Several similar results were obtained in previous studies. Inhibition against $E$. coli and Staphylococcus was observed in the case of silver nanoparticles synthesized using extract from Mentha piperita [57]. Acalypha indica and Solanum torvum extracts based synthesized silver nanoparticles showed high toxicity to E. coli [21] and Pseudomonas and Staphylococcus [58], respectively.

The mechanism by which silver nanoparticles show antibacterial activity is mainly due the positive charge on the $\mathrm{Ag}+$ ion. This is derived through the electrostatic attraction between positive charge of silver nanoparticles and negative charges on the cell membrane of microorganism [59-62]. The 
antibacterial activity of silver nanoparticles against Gram's negative bacteria is higher than that against Gram's positive bacteria. This may be due to the variation in the cell wall composition between Gram positive and negative bacteria.

The silver nanoparticles of leaf and leaf derived callus extracts of Allophylus serratus show highest antibacterial activity against Klebsiella pneumoniae followed by Pseudomonas aeruginosa and Staphylococcus aureus species.

\section{Conclusion}

Medicinal plants have medicinally important compounds in their different parts. The synthesis of nanoparticles using plants depends on the nature of plant such as its phytochemical content, special adaptation, and medicinal importance. In this study, we investigated eco-friendly and costeffective green synthesis of silver nanoparticles using leaf and leaf derived callus extract of medicinal plant $A$. serratus. Water soluble organic compounds present in the leaf and callus extracts were mainly responsible for synthesis of silver nanoparticles by reducing silver ions to nanosized silver particles. The UV-visible spectroscopy, XRD, SEM, EDS, and FTIR studies of the synthesized silver nanoparticles elucidated that the silver nanoparticles were crystalline in nature, spherical in shape with size ranging between 42 and $50 \mathrm{~nm}$, and stable. The synthesized silver nanoparticles exhibited antibacterial activity against Staphylococcus aureus, Bacillus subtilis, and Klebsiella pneumoniae and Pseudomonas aeruginosa strains. This green inexpensive and simple method can be used as alternative to chemical, physical, and microbial mediated methods used for production of silver nanoparticles.

\section{Competing Interests}

The authors declare that there is no conflict of interests regarding the publication of this paper.

\section{References}

[1] S. Ahmed, M. Ahmad, B. L. Swami, and S. Ikram, "A review on plants extract mediated synthesis of silver nanoparticles for antimicrobial applications: a green expertise," Journal of Advanced Research, vol. 7, no. 1, pp. 17-28, 2016.

[2] K. A. Khalil, H. Fouad, T. Elsarnagawy, and F. N. Almajhdi, "Preparation and characterization of electrospun PLGA/silver composite nanofibers for biomedical applications," International Journal of Electrochemical Science, vol. 8, no. 3, pp. 34833493, 2013.

[3] A. Ahmad, P. Mukherjee, S. Senapati et al., "Extracellular biosynthesis of silver nanoparticles using the fungus Fusarium oxysporum," Colloids and Surfaces B: Biointerfaces, vol. 28, no. 4, pp. 313-318, 2003.

[4] T. Klaus-Joerger, R. Joerger, E. Olsson, and C.-G. Granqvist, "Bacteria as workers in the living factory: metal-accumulating bacteria and their potential for materials science," Trends in Biotechnology, vol. 19, no. 1, pp. 15-20, 2001.

[5] S. W. P. Wijnhoven, W. J. G. M. Peijnenburg, C. A. Herberts et al., "Nano-silver-a review of available data and knowledge gaps in human and environmental risk assessment," Nanotoxicology, vol. 3, no. 2, pp. 109-138, 2009.

[6] M. Popescu, A. Velea, and A. Lorinczi, "Biogenic production of nanoparticles," Digest Journal of Nanomaterials and Biostructures, vol. 5, no. 4, pp. 1035-1040, 2010.

[7] B. Baruwati, V. Polshettiwar, and R. S. Varma, "Glutathione promoted expeditious green synthesis of silver nanoparticles in water using microwaves," Green Chemistry, vol. 11, no. 7, pp. 926-930, 2009.

[8] G. A. K. Reddy, J. M. Joy, T. Mitra, S. Shabnam, and T. Shilpa, "Nano silver-a review," International Journal of Advanced Pharmaceutics, vol. 2, no. 1, pp. 9-15, 2012.

[9] K. B. Narayanan and N. Sakthivel, "Biological synthesis of metal nanoparticles by microbes," Advances in Colloid and Interface Science, vol. 156, no. 1-2, pp. 1-13, 2010.

[10] K. Kalishwaralal, V. Deepak, S. Ram Kumar Pandian et al., "Biosynthesis of silver and gold nanoparticles using Brevibacterium casei," Colloids and Surfaces B: Biointerfaces, vol. 77, no. 2, pp. 257-262, 2010.

[11] D. A. Kumar, V. Palanichamy, and S. M. Roopan, "Green synthesis of silver nanoparticles using Alternanthera dentata leaf extract at room temperature and their antimicrobial activity," Spectrochimica Acta. Part A: Molecular and Biomolecular Spectroscopy, vol. 127, pp. 168-171, 2014.

[12] J. R. Nakkala, R. Mata, A. K. Gupta, and S. R. Sadras, "Biological activities of green silver nanoparticles synthesized with Acorous calamus rhizome extract," European Journal of Medicinal Chemistry, vol. 85, pp. 784-794, 2014.

[13] J. R. Nakkala, R. Mata, A. K. Gupta, and S. R. Sadras, "Green synthesis and characterization of silver nanoparticles using Boerhaavia diffusa plant extract and their antibacterial activity," Industrial Crops and Products, vol. 52, pp. 562-566, 2014.

[14] Q. Sun, X. Cai, J. Li, M. Zheng, Z. Chen, and C.-P. Yu, "Green synthesis of silver nanoparticles using tea leaf extract and evaluation of their stability and antibacterial activity," Colloids and Surfaces A: Physicochemical and Engineering Aspects, vol. 444, pp. 226-231, 2014.

[15] A. Nabikhan, K. Kandasamy, A. Raj, and N. M. Alikunhi, "Synthesis of antimicrobial silver nanoparticles by callus and leaf extracts from saltmarsh plant, Sesuvium portulacastrum L.", Colloids and Surfaces B: Biointerfaces, vol. 79, no. 2, pp. 488-493, 2010.

[16] V. Gopinath, D. MubarakAli, S. Priyadarshini, N. M. Priyadharsshini, N. Thajuddin, and P. Velusamy, "Biosynthesis of silver nanoparticles from Tribulus terrestris and its antimicrobial activity: a novel biological approach," Colloids and Surfaces B: Biointerfaces, vol. 96, pp. 69-74, 2012.

[17] R. Mariselvam, A. J. A. Ranjitsingh, A. Usha Raja Nanthini, K. Kalirajan, C. Padmalatha, and P. Mosae Selvakumar, "Green synthesis of silver nanoparticles from the extract of the inflorescence of Cocos nucifera (family: arecaceae) for enhanced antibacterial activity," Spectrochimica Acta - Part A: Molecular and Biomolecular Spectroscopy, vol. 129, pp. 537-541, 2014.

[18] B. Sadeghi and F. Gholamhoseinpoor, "A study on the stability and green synthesis of silver nanoparticles using Ziziphora tenuior (Zt) extract at room temperature," Spectrochimica Acta. Part A: Molecular and Biomolecular Spectroscopy, vol. 134, pp. 310-315, 2015.

[19] B. Ulug, M. Haluk Turkdemir, A. Cicek, and A. Mete, "Role of irradiation in the green synthesis of silver nanoparticles mediated by fig (Ficus carica) leaf extract," Spectrochimica Acta. 
Part A: Molecular and Biomolecular Spectroscopy, vol. 135, pp. 153-161, 2015.

[20] N. Geetha, T. S. Geetha, P. Manonmani, and M. Thiyagarajan, "Green synthesis of silver nanoparticles using Cymbopogan Citratus (Dc) Stapf. Extract and its antibacterial activity," Australian Journal of Basic and Applied Sciences, vol. 8, no. 3, pp. 324-331, 2014.

[21] C. Krishnaraj, E. G. Jagan, S. Rajasekar, P. Selvakumar, P. T. Kalaichelvan, and N. Mohan, "Synthesis of silver nanoparticles using Acalypha indica leaf extracts and its antibacterial activity against water borne pathogens," Colloids and Surfaces B: Biointerfaces, vol. 76, no. 1, pp. 50-56, 2010.

[22] V. Veeraputhiran, "Bio-Catalytic synthesis of silver nanoparticles," International Journal of ChemTech Research, vol. 5, no. 5, pp. 2555-2562, 2013.

[23] B. Sadeghi, A. Rostami, and S. S. Momeni, "Facile green synthesis of silver nanoparticles using seed aqueous extract of Pistacia atlantica and its antibacterial activity," Spectrochimica Acta - Part A: Molecular and Biomolecular Spectroscopy, vol. 134, pp. 326-332, 2015.

[24] S. A. Masurkar, P. R. Chaudhari, V. B. Shidore, and S. P. Kamble, "Rapid Biosynthesis of silver nanoparticles using Cymbopogan citratus (Lemongrass) and its Antimicrobial Activity," NanoMicro Letters, vol. 3, no. 3, pp. 189-194, 2011.

[25] T. Murashige and F. Skoog, "A revised medium for rapid growth and bio assays with tobacco tissue cultures," Physiologia Plantarum, vol. 15, no. 3, pp. 473-497, 1962.

[26] R. Veerasamy, T. Z. Xin, S. Gunasagaran et al., "Biosynthesis of silver nanoparticles using mangosteen leaf extract and evaluation of their antimicrobial activities," Journal of Saudi Chemical Society, vol. 15, no. 2, pp. 113-120, 2011.

[27] K. Roy, S. Biswas, and P. C. Banerjee, “"Green” synthesis of silver nanoparticles by using grape (Vitis vinifera) fruit extract: Characterization of the particles and study of antibacterial activity," Research Journal of Pharmaceutical, Biological and Chemical Sciences, vol. 4, no. 1, pp. 1271-1278, 2013.

[28] V. K. Shukla, S. Pandey, and A. C. Pandey, "Green synthesis of silver nanoparticles using neem leaf (Azadirachta indica) extract," in Proceedings of the 1st International Conference on Advanced Nanomaterials and Nanotechnology (ICANN '09), pp. 43-49, Assam, India, December 2009.

[29] N. Namratha and P. V. Monica, "Synthesis of silver nanoparticles using Azadirachta indica (Neem) extract and usage in water purification," Asian Journal of Pharmaceutical Technology and Innovation, vol. 3, pp. 170-177, 2013.

[30] A. Lalitha, R. Subbaiya, and P. Ponmurugan, "Green synthesis of silver nanoparticles from leaf extract Azhadirachta indica and to study its anti-bacterial and antioxidant property," International Journal of Current Microbiology and Applied Sciences, vol. 2, pp. 228-235, 2013.

[31] G. Singhal, R. Bhavesh, K. Kasariya, A. R. Sharma, and R. P. Singh, "Biosynthesis of silver nanoparticles using Ocimum sanctum (Tulsi) leaf extract and screening its antimicrobial activity," Journal of Nanoparticle Research, vol. 13, no. 7, pp. 29812988, 2011.

[32] D. Philip and C. Unni, "Extracellular biosynthesis of gold and silver nanoparticles using Krishna tulsi (Ocimum sanctum) leaf," Physica E: Low-Dimensional Systems and Nanostructures, vol. 43, no. 7, pp. 1318-1322, 2011.

[33] D. Cruz, P. L. Falé, A. Mourato, P. D. Vaz, M. Luisa Serralheiro, and A. R. L. Lino, "Preparation and physicochemical characterization of Ag nanoparticles biosynthesized by Lippia citriodora
(Lemon Verbena)," Colloids and Surfaces B: Biointerfaces, vol. 81, no. 1, pp. 67-73, 2010.

[34] R. Prasad and V. S. Swamy, "Antibacterial activity of silver nanoparticles synthesized by bark extract of Syzygium cumini," Journal of Nanoparticles, vol. 2013, Article ID 431218, 6 pages, 2013.

[35] K. Roy, C. K. Sarkar, and C. K. Ghosh, "Plant-mediated synthesis of silver nanoparticles using parsley (Petroselinum crispum) leaf extract: spectral analysis of the particles and antibacterial study," Applied Nanoscience, vol. 5, no. 8, pp. 945951, 2015.

[36] P. Scherrer, "Determination of the size and internal structure of colloidal particles using X-rays," Nachrichten von der Gesellschaft der Wissenschaften zu Göttingen, vol. 1918, pp. 98100, 1918 (German).

[37] S. L. Smitha, D. Philip, and K. G. Gopchandran, "Green synthesis of gold nanoparticles using Cinnamomum zeylanicum leaf broth," Spectrochimica Acta - Part A: Molecular and Biomolecular Spectroscopy, vol. 74, no. 3, pp. 735-739, 2009.

[38] G. Annadurai, G. GnanaJobith, S. Rajeshkumar, and C. Kannan, "Preparation and characterization of fruit-mediated silver nanoparticles using pomegranate extract and assessment of its antimicrobial activities," Journal of Environmental Nanotechnology, vol. 2, no. 1, pp. 4-10, 2013.

[39] M. Vanaja and G. Annadurai, "Coleus aromaticus leaf extract mediated synthesis of silver nanoparticles and its bactericidal activity," Applied Nanoscience, vol. 3, no. 3, pp. 217-223, 2013.

[40] D. Philip, "Mangifera indica leaf-assisted biosynthesis of welldispersed silver nanoparticles," Spectrochimica Acta Part A: Molecular and Biomolecular Spectroscopy, vol. 78, no. 1, pp. 327331, 2011.

[41] S. S. Shankar, A. Ahmad, and M. Sastry, "Geranium Leaf Assisted Biosynthesis of Silver Nanoparticles," Biotechnology Progress, vol. 19, no. 6, pp. 1627-1631, 2003.

[42] D. Philip, "Biosynthesis of Au, Ag and Au-Ag nanoparticles using edible mushroom extract," Spectrochimica Acta. Part A, vol. 73, no. 2, pp. 374-381, 2009.

[43] K. Paulkumar, S. Rajeshkumar, G. Gnanajobitha, M. Vanaja, C. Malarkodi, and G. Annadurai, "Biosynthesis of silver chloride nanoparticles using Bacillus subtilis MTCC 3053 and assessment of its antifungal activity," ISRN Nanomaterials, vol. 2013, Article ID 317963, 8 pages, 2013.

[44] S. Kaviya, J. Santhanalakshmi, B. Viswanathan, J. Muthumary, and K. Srinivasan, "Biosynthesis of silver nanoparticles using citrus sinensis peel extract and its antibacterial activity," Spectrochimica Acta-Part A: Molecular and Biomolecular Spectroscopy, vol. 79, no. 3, pp. 594-598, 2011.

[45] J. Das, M. Paul Das, and P. Velusamy, "Sesbania grandiflora leaf extract mediated green synthesis of antibacterial silver nanoparticles against selected human pathogens," Spectrochimica ActaPart A: Molecular and Biomolecular Spectroscopy, vol. 104, pp. 265-270, 2013.

[46] M. R. Bindhu and M. Umadevi, "Synthesis of monodispersed silver nanoparticles using Hibiscus cannabinus leaf extract and its antimicrobial activity," Spectrochimica Acta - Part A: Molecular and Biomolecular Spectroscopy, vol. 101, pp. 184-190, 2013.

[47] S. Singha, K. Neog, P. P. Kalita, N. Talukdar, and M. P. Sarma, "Biological synthesis of silver nanoparticles by Neptunia oleraceae," International Journal of Basic and Applied Biology, vol. 2, no. 2, pp. 55-59, 2014. 
[48] R. Janardhanan, M. Karuppaiah, N. Hebalkar, and T. N. Rao, "Synthesis and surface chemistry of nano silver particles," Polyhedron, vol. 28, no. 12, pp. 2522-2530, 2009.

[49] W. Wei, X. Mao, L. A. Ortiz, and D. R. Sadoway, "Oriented silver oxide nanostructures synthesized through a template-free electrochemical route," Journal of Materials Chemistry, vol. 21, no. 2, pp. 432-438, 2011.

[50] J. Y. Song and B. S. Kim, "Rapid biological synthesis of silver nanoparticles using plant leaf extracts," Bioprocess and Biosystems Engineering, vol. 32, no. 1, pp. 79-84, 2009.

[51] R. S. R. Isaac, G. Sakthivel, and C. Murthy, "Green synthesis of gold and silver nanoparticles using averrhoa bilimbi fruit extract," Journal of Nanotechnology, vol. 2013, Article ID 906592, 6 pages, 2013

[52] P. Prakash, P. Gnanaprakasam, R. Emmanuel, S. Arokiyaraj, and M. Saravanan, "Green synthesis of silver nanoparticles from leaf extract of Mimusops elengi, Linn. for enhanced antibacterial activity against multi drug resistant clinical isolates," Colloids and Surfaces B: Biointerfaces, vol. 108, pp. 255-259, 2013.

[53] D. S. Balaji, S. Basavaraja, R. Deshpande, D. B. Mahesh, B. K. Prabhakar, and A. Venkataraman, "Extracellular biosynthesis of functionalized silver nanoparticles by strains of Cladosporium cladosporioides fungus," Colloids and Surfaces B: Biointerfaces, vol. 68, no. 1, pp. 88-92, 2009.

[54] S. Mandal, S. Phadtare, and M. Sastry, "Interfacing biology with nanoparticles," Current Applied Physics, vol. 5, no. 2, pp. 118-127, 2005.

[55] X. Gao, J. J. Yourick, V. D. Topping et al., “Toxicogenomic study in rat thymus of $\mathrm{F} 1$ generation offspring following maternal exposure to silver ion," Toxicology Reports, vol. 2, pp. 341-350, 2014.

[56] H. M. Ibrahim, "Green synthesis and characterization of silver nanoparticles using banana peel extract and their antimicrobial activity against representative microorganisms," Journal of Radiation Research and Applied Sciences, vol. 8, no. 3, pp. 265275, 2015.

[57] D. MubarakAli, N. Thajuddin, K. Jeganathan, and M. Gunasekaran, "Plant extract mediated synthesis of silver and gold nanoparticles and its antibacterial activity against clinically isolated pathogens," Colloids and Surfaces B: Biointerfaces, vol. 85, no. 2, pp. 360-365, 2011.

[58] K. Govindaraju, S. Tamilselvan, V. Kiruthiga, and G. Singaravelu, "Biogenic silver nanoparticles by Solanum torvum and their promising antimicrobial activity," Journal of Biopesticides, vol. 3, no. 1, pp. 394-399, 2010.

[59] R. W. Raut, N. S. Kolekar, J. R. Lakkakula, V. D. Mendhulkar, and S. B. Kashid, "Extracellular synthesis of silver nanoparticles using dried leaves of pongamia pinnata (L) pierre," Nano-Micro Letters, vol. 2, no. 2, pp. 106-113, 2010.

[60] C. L. Fox, "Silver sulfadiazine-a new topical therapy for Pseudomonas in burns. Therapy of Pseudomonas infection in burns," Archives of Surgery, vol. 96, no. 2, pp. 184-188, 1968.

[61] T. Hamouda, A. Myc, B. Donovan, A. Y. Shih, J. D. Reuter, and J. R. Baker Jr., "A novel surfactant nanoemulsion with a unique non-irritant topical antimicrobial activity against bacteria, enveloped viruses and fungi," Microbiological Research, vol. 156, no. 1, pp. 1-7, 2001.

[62] P. Dibrov, J. Dzioba, K. K. Gosink, and C. C. Häse, "Chemiosmotic mechanism of antimicrobial activity of Ag+ in Vibrio cholerae," Antimicrobial Agents and Chemotherapy, vol. 46, no. 8, pp. 2668-2670, 2002. 

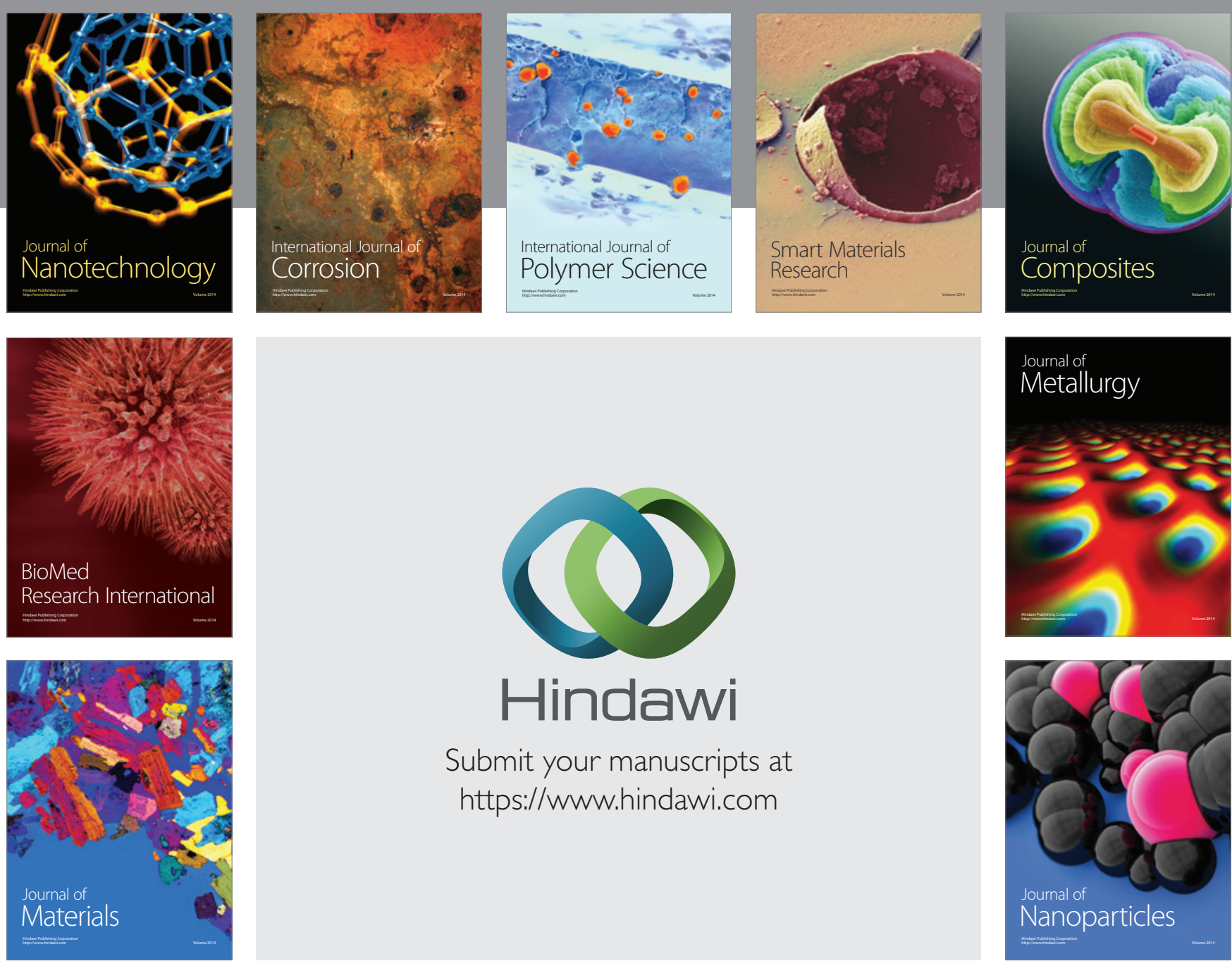

\section{Hindawi}

Submit your manuscripts at

https://www.hindawi.com

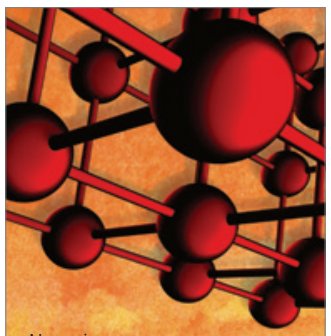

Materials Science and Engineering
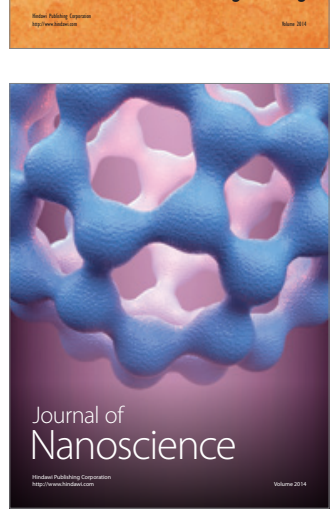
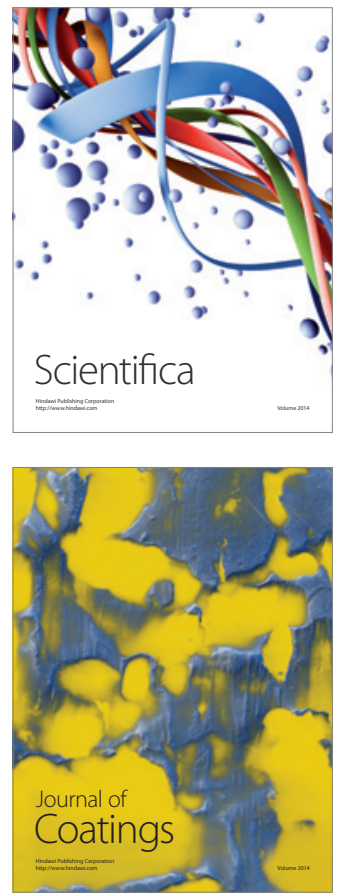
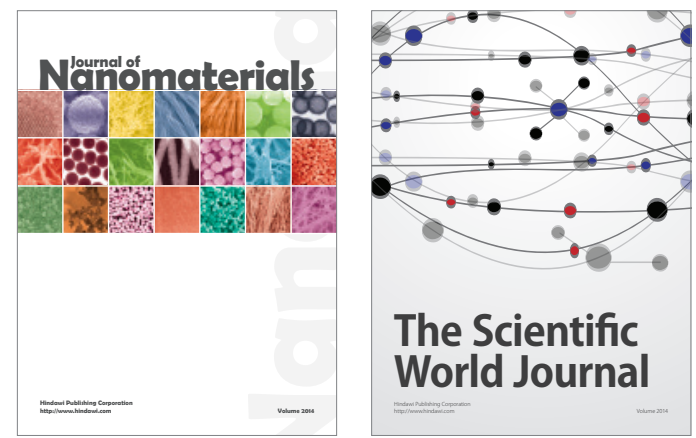

The Scientific World Journal
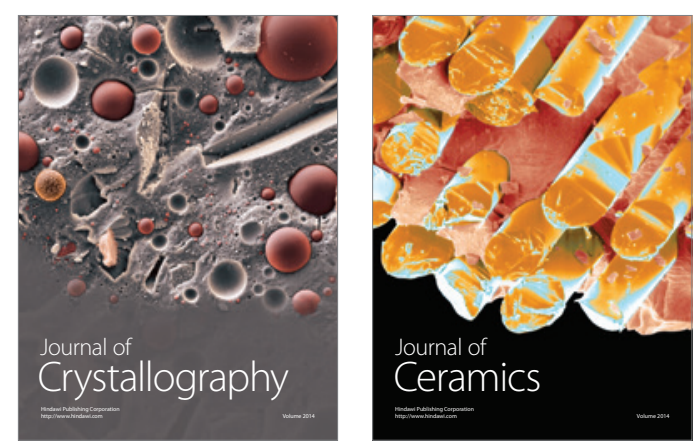
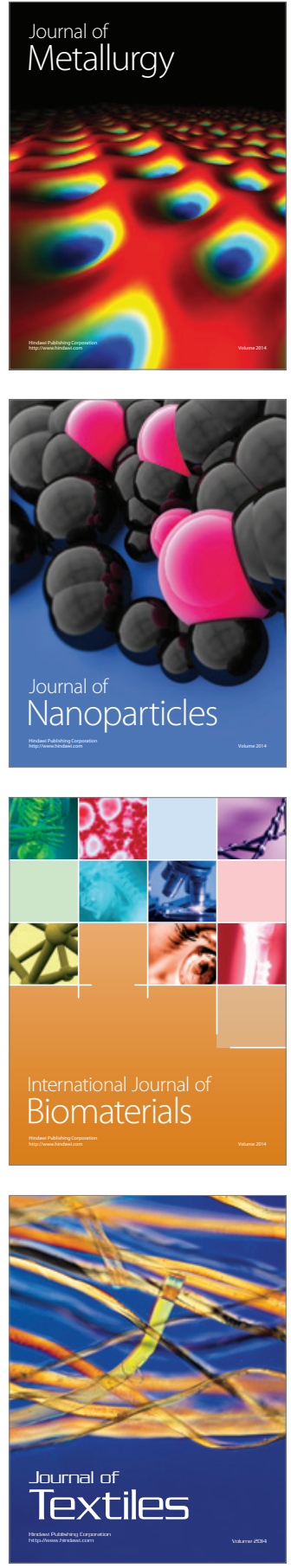